\title{
A Study on the Benefits of Transit Oriented Development in Malaysia And Incoporation of Those Benefits in Planning
}

\author{
Christy P. Gomez ${ }^{1, *}$, Masitah Omar ${ }^{2}$, Rameson Nallusamy ${ }^{3}$ \\ ${ }^{1}$ Assoc. Prof. Universiti Tun Hussein Onn Malaysia, 86400 Batu Pahat, Johor, Malaysia \\ ${ }^{2,3}$ Researcher, Universiti Tun Hussein Onn Malaysia, 86400 Batu Pahat, Johor, Malaysia
}

\begin{abstract}
In Malaysia Transit Oriented Development (TOD) is increasingly becoming a priority for developers and property companies to lead urban planning towards creating a quality, prosperous and sustainable living environment. Malaysia is still relying heavily on traditional planning for its infrastructure development. The objectives of this study are to analyze current planning related to TOD in Malaysia and identify the economic, social and environmental benefits of TOD. A mixed method research approach was used. Quantitative data was collected using questionnaire survey and qualitative data obtained through interviews. The respondents for the questionnaire survey aimed at determining the benefits of TOD consisted of the transit community using the KL Sentral Station. Whilst the investigation on the current planning by the local authority with regards to TOD was undertaken based on data obtained from Johor state local council town planners. The results indicate that from a general perspective social benefits are perceived to be the greatest and from a personal perspective the environmental benefits are greatest. Whilst the current planning regarding TOD in Malaysia is very much at initial planning stages in the case of Johor state and the main emphasis is on reducing the number of people using private transport vehicles on the road. This study provides a reliable transit community perspective regarding the real economic, social and environmental benefits of TODs and provides a timely reflection for local council town planner and key stakeholders to review thier approach to leverage on the wider benefits of TOD.
\end{abstract}

\section{Introduction}

Transportation is a crucial element to be considered for most development, especially in urban environments. In view of the globalization era it can be seen the development of technological sophistication as well as economic growth has contributed to the population that is increasingly vibrant. Therefore the demand for residential and business development in the city centre and its surrounding tends to rise. This situation creates pressure on the existing development in the city, which encourages urban sprawl. As population increases, it creates the demand for public transportation to commute from home to work, shopping and even recreation. Therefore to support the growth of urban population rise, Transit Oriented Development (TOD) is a potential solution. It is primarily expected to help in reducing dependability on private vehicles and encourage public transportation and walking as a lifestyle in a city [1].

The concept of TOD is not new in Malaysia. The National Physical Plan (Policy NPP27 in 2005, and Policy NPP32 in 2010) clearly states that "Transit Oriented Development shall be promoted as the basis for urban land use planning to ensure viability of public transport". From a policy perspective, the emphasis on TOD is also clearly outlined in the state structure plans and local plans, for example the Selangor Structure Plan
2020, and KL City Plan 2020, as well as in regional plans, for example Iskandar Region's Comprehensive Development Plan (CDP).

From a research perspective, there has been much previous work focused on the principles that are important in determining TOD typologies. Having reviewed TOD typology literature, [2] note that the following principles are important in determining a TOD typology, they are: availability and connectivity (intermodal) of public transport services; land use mix (diversity); residential density; land use intensity for employment; and pedestrian connectivity.

TOD is a type of development which is designed mainly to encourage the use of public transport and create a pedestrian-friendly urban environment [3]. According to the TCRP Report 102 [3], TODs that emphasize a pedestrian-oriented environment reinforce the use of public transportation. TODs that are within comfortable walking distance, make it convenient for residents and employees to travel by transit, bicycle or foot [3]. This view is shared by [2], referring to TODs as being designed mainly to encourage the use of public transit and create a pedestrian-friendly urban environment. It is noted by [4] that in referring to the TOD concept over the years various terms such as "transit village", "transit-friendly design", and "transitsupportive development" have been used. However, they

* Corresponding author: cpgomez21@gmail.com 
[4] note that TOD is the most widely-used and the most popular term.

It cannot be denied that TOD has slightly affected three large areas of concern, which are: economic development, environmental and social needs. TOD is principally aimed at providing for a vibrant, liveable community. TOD generally provides a mix of residential and commercial uses and is designed to make public transit successful, enhance the convenience and safety of walking and bicycling. The key components of TOD can be condensed into the concept of complete communities. Complete communities have the following key characteristics [5]:

(i) Quality transit facilities and service.

(ii) Walkable-a high-quality pedestrianenvironment.

(iii) Destinations-complete communities with a community center and the right mix of uses.

(iv) Compact-with the highest densities closest to transit.

(v) Parking that is carefully located, designed, and managed.

The first person who proposed the concept of TOD is an American architect [6] and therefore many American cities such as San Francisco and Atlanta were the first to adopt TOD planning principles. It is only later that it gained much attention in Europe. TOD is defined generally as walkable, compact and mixed use development adjacent to a transit station [3]. According to the TCRP Report 102 [3], a transit station becomes a node which connects places in the city, adjacent area to the transit station and creates high opportunity for commercial and public services, and some Asian governments have begun to use this concept as their primary urban planning method.

According to [7], the construction of the city is a place for the public and it is one of the main aspects of designing the city. Wherein urban spatial planning determines the spatial structure, ultimately determining the level of environmental pollution of the city. The implication is that the spatial plan of the city is very much related to the organization of traffic which affects environmental pollution. Currently in Malaysia most TODs are being developed within high-density populated urban areas. Although development is happening in the suburbs, there seems to be a lack of high connectivity that can sustain the TOD concept. There are reasons to believe the balance could shift as we will need to redevelop our urban and suburban centres to accommodate more growth. A common denominator in planning is the understanding that without transit, neighbourhoods will be overrun with traffic.

\subsection{Backgroud of study}

Urban sprawl and auto mobilization have led to an increase in the frequency of journeys made by private motorized vehicles. This leads to increased congestion, higher emissions of greenhouse gases. The significant final implication is in terms of negative environmental, social and economic impacts. The way forward needs to be sustainable growth, and a crucial element for a sustainable future is seen as the coordination between land use planning and transportation system planning. An assumption in this research is that the key enabler towards this end is Transit Oriented Development (TOD).

\subsection{Research gap and issues}

Current development that does not focus on TOD tends to contribute to increasing reliance on private transport and road networks that are congested and contribute to increasing pollution and less sustainable development. Additionally, the "one-size fits all" approach to TOD and the focus on developing existing train stations into TODs is not recommended as it does not allow for developing TOD sites based on proper assessment [2].

Several cases have proven that the implementation of transit community concept is still far from achieving its primary planning target. Much is left to be desired in providing sufficient community benefit, especially to the local people. It is important that regardless of the theoretical benefits and potential of TODs, it is important to analyse the actual outcomes of recent TOD initiatives with respect to transit station communities. In most developing countries like Malaysia, the approach to planning for future development in cities is often not undertaken in an integrated manner, resulting in huge dependency on road transport, which additionally becomes congested.

\section{Characteristics and benefits of TOD}

It is noted by [8] that a good TOD that meets established principles of TOD would ensure that the objectives of that development are achieved and the residents' quality of life are improved. They identify a number of characteristics of TODs as:

- Grid street pattern;

- Higher population densities;

- Surface parking and efficient parking management;

- Pedestrian and bicycle-oriented design;

- Mixed-housing types, including multi- family;

- Horizontal (side by side) and vertical (within the same building) mixed use;

- Office and retail, particularly on main streets.

\subsection{Criteria of TOD}

The main elements of TOD are diversity, density and design. Diversity is in the form of mixed use development, density in the form of more residence and jobs while design in the form of good street connectivity for pedestrians [10]. A number of researchers have formulated key criteria or characteristics that can be used for measuring the TOD-ness of an area or transit statiton vicinity. The following eight criteria formulated by Singh [11] has been proposed by them to design a measurement index tool. 
i. Density - Urban densities are important for developing TOD.

ii. Land use diversity - Land use diversity creates a vibrant/ lively place out of a node.

iii. Walkability and Cyclability - Design of urban space that is walkable and cyclable are necessary for TODs.

iv. Economic development - Higher economic development in an area leads to higher TOD-ness.

v. Capacity utilisation of transit - Higher ridership indicates higher TOD-ness.

vi. User-frienliness of transit system - A user-friendly transit system is necessary to encourage people to use transit.

vii. Access and accessibility - A node with better access and that provides high access and frequency of service has increased chances of creating a successful TOD.

viii. Parking at station - Parking supply for cycles and cars will help more people to use transit for their longer commutes.

\subsection{TOD Environmental Benefits}

The concern for the environment is prioritised through certain mechanisms. TODs' characteristics augur well for giving prominence to development that can reduce the impact to the environment, considered here as benefits. Some of the benefits are listed below:

- The priority for public transport contributes significantly in the reduction of pollution emissions [12].

- TOD serves as an optimal solution as it is an avenue for creating a green transportation system [13].

- TOD provides sustainable transport and also provides the opportunity for communities to have "co-located" facilities for living, working, shopping and relaxing [14].

\subsection{TOD Economic Benefits}

TOD concentrates economic development in specific corridors, thereby reducing sprawl and increasing the efficiency of public service delivery. Some of the economic benefits of TOD include the following:

- TODs increase transit ridership which consequently boost fare revenues, bringing additional income into localities and transit systems [15].

- TOD projects can significantly boost the value of real estate around transit centres. [15].

- TODs contribute to the development of vibrant neighbourhoods with residential and commercial components that can expand a locality's tax base. [15].

- As the volume of public transportation systems will increase because of TOD, thereby this indirectly contributes to the economic efficiency of such systems [16].

\subsection{TOD Social Benefits}

TOD development is a development that focuses on its inhabitants having an active lifestyle. In comparison with traditional transportation development, TOD provides fast, one-to-one and more efficient trips. The social benefits of TOD include the following:

- The user can reduce travel time and spend more time with the family [12].

- Fosters its inhabitants with an active lifestyle [12].

- TOD provides fast, one-to-one and more efficient trips [12]

- TODs contribute to the possibility of maximizing use of limited transportation dollars [12].

- TODs generally provide lower parking costs and reduces congestion [17].

- TODs feature good transit, cultural amenities, affordable housing enhancing the concept of liveable communities [17].

\subsection{Rationale for development of TOD in Malaysia}

One of the key missions of the Malaysian Government's Transformation Programme (GTP) is to improve the urban public transportation system. There is critical traffic congestion in major cities that forces residents to spend almost one to four hours per day on commuting (Tong, 2014). It is noted by [20] that this on-going issue has spurred the need for government and private developers to promote TOD in Malaysia. However, nationwide, only 5 percent of Malaysians use public transportation [20]. Additionally, although the benefits of TOD are well recognized, the emphasis on incorporating features that leverage on the potential sustainable benefits of TODs leaves much to be desired. Below are a list of five TODs which are planned for in the Malaysian real estate market in addition to the existing estabilshed KL Sentral and Subang Jaya.
i. Latitude8
ii. TREC
iii. KL118
iv. Bandar Malaysia
v. KL Metropolis

TOD development boosts strategic, sustainable, spatial and economic establishments in a transformative way towards achieving high-income developed country status without compromising for short term goals. Consumer interests are the main agenda for a prosperous and improved quality of life. The development of TODs will ensure greater sustainability of the country through the preservation of natural assets and the invaluable tradition of preserving national heritage, as fundamentally greater emphasis is on sustainable development. 


\section{Research Methodology}

In this study, mixed methodology was used, both quantitative and qualitative. The respondents for the questionnaire survey aimed at determining the benefits of TOD consisted of the transit community using the KL Sentral Station. KL Sentral Station was chosen as it ranks well above the other Malaysian TODs in terms of mixed-use development, relatively high population density and accessibility. Hence, the transit community at KL Sentral would be well positioned to provide quality feedback. Whilst the investigation on the current planning by the local authority with regards to TOD was undertaken based on data obtained from Johor state local council town planners. Since the policy towards implementation of TOD is a top-down approach, beginning with the National Physical Plan, picking any one particular council was justified. Primary data was from interviews with local authority town planners and secondary data from master plan of local authorities.

Purposeful sampling of respondents commuting at the KL Sentral transit station was undertaken based on their willingness to participate in the questionnarie survey. Data collection in this study involved 62 respondents representing 62 sets of questionnaires distributed through two face-to-face and Google Form methods around the central KL area on 12 April 2018. A total of 20 sets of completed questionnaires that were distributed personally were collected immediately and 42 replies from respondents who were approached at KL Sentral sent their responses through Google Form on the same day. The data consisted of the individual respondent's evaluation of the benefits of TOD both from a personal and general perspective. The data was analysed using microsoft excel to determine the mean score.

Two indepth interviews were conducted with town planning officials from Johor state government. The interviews were semi-structured and the data was recorded and transcribed before being analysed using content analysis technique.

\section{Analysis and results}

Table 1 lists the result of the benefits with the highest mean scored for environmental benefits of TOD in Malaysia from a personal and general perspective. The benefit of TOD in terms of improving the quality of urban design and enhancing the aesthetic beauty of the urban landscape obtained the highest mean score of 4.15 from a personal perspective. Whilst from a general perspective, the respondent's results showed that the highest benefit is that TOD reduces the number of cars in the streets and helps to reduce noise from vehicles and that TOD contributes to more efficient use of land.
Table.1 Environmental Benefits

\begin{tabular}{|c|l|c|}
\hline Types & \multicolumn{1}{|c|}{ Result } & $\begin{array}{c}\text { Higher } \\
\text { Value of } \\
\text { Mean }\end{array}$ \\
\hline General & $\begin{array}{l}\text { TOD reduces the number of cars in streets } \\
\text { and thus helps reduce noise from vehicles. }\end{array}$ & 4.03 \\
\cline { 2 - 3 } & $\begin{array}{l}\text { TOD contributes to more efficient use of } \\
\text { land. }\end{array}$ & 4.03 \\
\hline Personal & $\begin{array}{l}\text { TOD improves the quality of urban design } \\
\text { and enhances the aesthetic beauty of the } \\
\text { urban landscape. }\end{array}$ & 4.15 \\
\hline
\end{tabular}

Table 2 lists the result of the benefits with the highest mean scored for economic benefits of TOD in Malaysia from a personal and general perspective. The benefit of TOD in terms of providing better access for local businesses and retail for the transit community obtained the highest mean score of 3.95 from a personal perspective. Whilst from a general perspective, the respondent's results showed that the highest benefit is that TOD encourages increase in volume of public transportation systems.

Table. 2 Economic Benefits

\begin{tabular}{|c|l|c|}
\hline \multicolumn{1}{|c|}{ Types } & \multicolumn{1}{|c|}{ Result } & $\begin{array}{c}\text { Higher } \\
\text { Value of } \\
\text { Mean }\end{array}$ \\
\hline General & $\begin{array}{l}\text { TOD encourages increase in volume of } \\
\text { public transportation systems. }\end{array}$ & 4.08 \\
\hline Personal & $\begin{array}{l}\text { TOD provides me better access local } \\
\text { businesses and retail. }\end{array}$ & 3.95 \\
\hline
\end{tabular}

Table 3 lists the result of the benefits with the highest mean scored for social benefits of TOD in Malaysia from a personal and general perspective. The benefit of TOD in terms of having key service characteristics that increases transit community mobility obtained the highest mean score of 4.08 from a personal perspective. Whilst from a general perspective, the respondent's results showed that the highest benefit is that TOD provides much needed mobility options for young people, the elderly and people who do not own cars.

Table. 3 Social Benefits

\begin{tabular}{|c|l|c|}
\hline Types & \multicolumn{1}{|c|}{ Result } & $\begin{array}{c}\text { Higher } \\
\text { Value of } \\
\text { Mean }\end{array}$ \\
\hline General & $\begin{array}{l}\text { TOD provides much needed mobility } \\
\text { options for young people, the elderly and } \\
\text { people who do not own cars. }\end{array}$ & 4.11 \\
\hline Personal & $\begin{array}{l}\text { TOD has key service characteristics that } \\
\text { increases my mobility }\end{array}$ & 4.08 \\
\hline
\end{tabular}

Analysis of data on the investigation regarding the current planning based on interview data from the Johor state local authority town planners. Excerpts of the interview are provided below:

How are Local Authorities (PBT's) doing their current planning in relation to Transport Oriented Development?

R1: ........In the spatial planning of the country - the structural design has been incorporated into the TOD design as another development space. The local plan of 
the district under review has also taken into account the TOD proposal. Referring to RD Batu Pahat, which is currently in the program publicity and public participation [phase]. For the new Johor area, the Iskandar Sentral Integrated Fleet Terminal Special Area Plan 2025 has devised a comprehensive TOD plan............

What are the proposed criteria needed to make the area a TOD?

R1: .......The proposed criteria for placement have been studied in RTD and RKK studies through various stages. * Refer to the study. ..........

What are the most important characteristics needed to declare that area as TOD?

R2..... TOD is a catalyst for development with mixed development. The city planning department has set up guidelines on mix development and vertical development to enable the suitability of TOD......

The main summary of the analysis of interview data is provided below:

(i) TOD planning is a development trend in developed countries but in the context of the state government is still in the planning stage and measurement of benefits has not yet been made.

(ii) The main aim of implementing TODs is to reduce the mode of transport in a city from 80:50 to 50:50 or lower and provide facilities for residents to get better transport facilities

\section{Conclusion}

From a general perspective the transit community perceives that the main social benefit is in terms of TOD providing the much needed mobility options for young people, the elderly and people who do not own cars. Whilst from a personal perspective the environmental benefits are viewed to be the greatest; as TOD is seen to improve the quality of urban design and enhance the aesthetic beauty of the urban landscape. From the economic perspective the focus is on accessibility and provision of alternative transport that allows for higher volume in terms of people mobility by a single system. Hence, it is the social and environmental benefits that are seen as being most significant based on the current implementation of TOD in Malaysia.

In terms of planning, the current planning by the local authorities with regards to TOD currently is mainly focused on reducing the mode of transport in a city from $80: 50$ to $50: 50$ in the use of private transport. However, even this main official target for promoting TOD is still very much in the planning stages at the local council levels.

On the whole, the outcomes of this research provides some initial insights as to the extent of the transit community's view on the current benefits provided by transit oriented development. Wherein, the bigger impact of the benefits of TOD is very much experienced within the social and environmental realm and not so much within the economic realm. Whilst, it is evident that the planning to incorporate TODs is not being undertaken within a wider and integrated mode to incorporate joint action of different key stakeholders to contribute to enhancing sustainable development in a more holistic sense.

\section{References}

1. T. Litman, Evaluating Public Transit Benefits and Costs - Best Practices Guidebook 24 July 2018, (Victoria Transport Policy Institute, 2018)

2. Md. Kamruzzaman, D. Baker, S. Washington, G. Turrell, J. of Transp. Geo., 34, 54-70 (2014)

3. R. Cervero, Transit-oriented development in the United States: experiences, challenges, and prospects. Report 102. (Transit Cooperative Research Program, Washington, DC, 2004)

4. A. Nasri, L. Zhang, Trnspt. Policy 32, 172-179 (2014)

5. W. DeCoursey and L. Athey, Transit Oriented Design-Illustrations of TOD characteristics: A working paper 2007 (Institute for Public Administration College of Human Services, Education \& Public Policy, University of Delaware, 2007)

6. P. Calthorpe, The Next American Metropolis: Ecology, Community, and Planning (Princeton, NJ, Princeton Architectural Press, 1994). .

7. D.S. Vale, J. of Transp. Geo., 45, 70-80 (2015)

8. J. L. Renne, Local Env.-The Int. J. of Justice and Sustbty., 14:1, 1-15 (2009)

9. 10 ?

10. R. Cervero, K. Kockelman, Transpn Res., 2 (3), 199-219 (1997)

11. Y.J. Singh, A. Lukman, J. Flacke, M. Zuidgeest, M.F.A.M. Van Maarseveen, Transp. Policy 56, 96$111(2017)$

12. W.M. Wey, Y.H. Chiu, Hab. Int. 38, 106-118 (2013)

13. Y.T. Peng, Z.C. Li, K. Choi, Transp. Rsch. Pt. B 000, 1-22 (2017)

14. S. Shastry, Spatial assessment of transit Oriented develpoment in Ahmedabad, India (MSc Thesis, 2010)

15. S. Zimbabwe, A. Anderson, Planning for TOD at regional scale: the big picture (The center for transit-oriented development, 2007)

16. P. Calthorpe, The next American metropolis (New York: Princeton Architectural Press, 1993)

17. B. Griffiths, C. Curtis, Urb. Policy \& Rsch. (2017) 